\title{
Correction to: Undersown cover crops have limited weed suppression potential when reducing tillage intensity in organically grown cereals
}

\author{
J. Salonen $(\mathbb{D})$ E. Ketoja
}

Published online: 5 September 2019

(C) The Author(s) 2019

\section{Correction to: Organic Agriculture \\ https://doi.org/10.1007/s13165-019- \\ 00262-6}

The original version of this article unfortunately contained layout errors in Figure 5.

The correct figure is shown below.

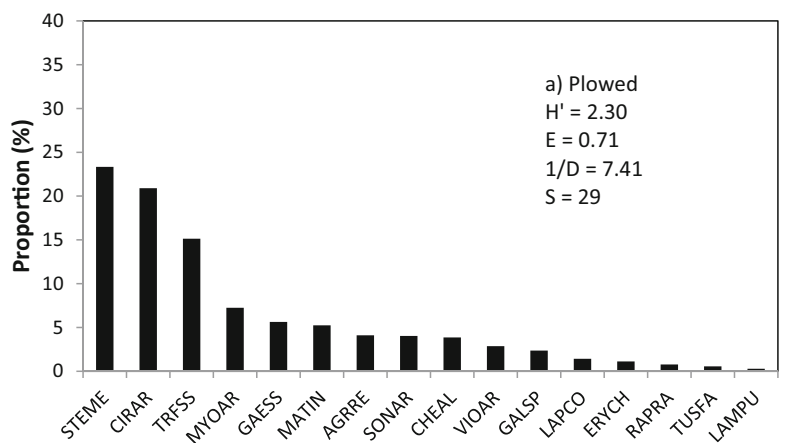

Fig. 5 Comparison of weed diversity between plowed plots (a) and reduced tillage (b) using Shannon index for diversity $\left(\mathrm{H}^{\prime}\right)$ and evenness (E) and Simpson's index for dominance (D) calculated using biomass values for a total number of observed weed species

The online version of the original article can be found at https://doi.org/10.1007/s13165-019-00262-6

J. Salonen $(\bowtie) \cdot$ E. Ketoja

Natural Resources Institute Finland (Luke), FI-31600 Jokioinen, Finland

e-mail: jukka.salonen@luke.fi

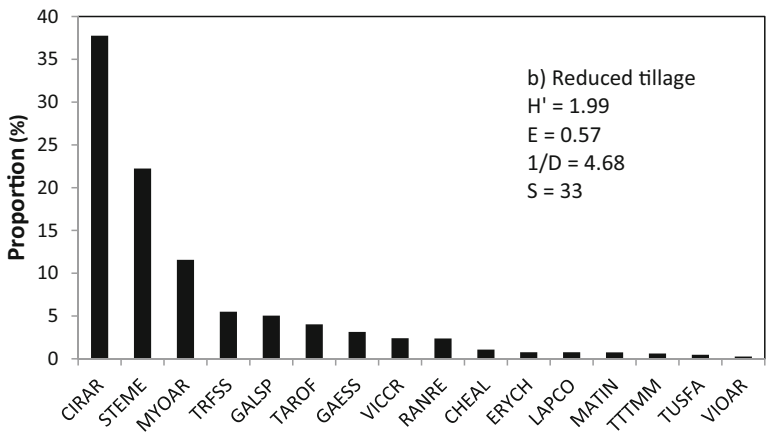

(S). Biomass shares of the 16 most abundant species in spring wheat in 2017 are presented. EPPO codes for weed species available at: https://gd.eppo.int/

The original article has been corrected.

Publisher's note Springer Nature remains neutral with regard to jurisdictional claims in published maps and institutional affiliations. 